\title{
Erratum to: Hypofractionated radiosurgery has a better safety profile than single fraction radiosurgery for large resected brain metastases
}

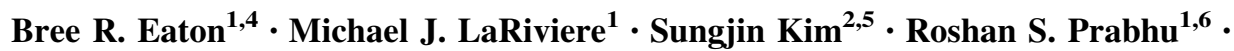
Kirtesh Patel $^{1} \cdot$ Shravan Kandula $^{1} \cdot$ Nelson Oyesiku $^{3} \cdot$ Jeffrey Olson $^{3}$.

Walter Curran $^{1} \cdot$ Hui-Kuo Shu ${ }^{1} \cdot$ Ian Crocker $^{1}$

Published online: 23 April 2015

(C) Springer Science+Business Media New York 2015

\section{Erratum to: J Neurooncol}

\section{DOI 10.1007/s11060-015-1767-4}

The second author's name was incorrect in the original publication. It is correct in this erratum.

The online version of the original article can be found under doi:10.1007/s11060-015-1767-4.

Bree R. Eaton

brupper@emory.edu

1 Department of Radiation Oncology, Winship Cancer Institute of Emory University, Atlanta, GA, USA

2 Department of Biostatistics and Bioinformatics, Winship Cancer Institute of Emory University, Atlanta, GA, USA

3 Department of Neurosurgery, Winship Cancer Institute of Emory University, Atlanta, GA, USA

4 Massachusetts General Hospital, Harvard Medical School, 55 Fruit Street, LL2, Boston, MA 02114, USA

5 Biostatistics and Bioinformatics Research Center, Cedars-Sinai Medical Center, Los Angeles, CA, USA

6 Southeastern Radiation Oncology Group, Levine Cancer Institute, Charlotte, NC, USA 